\title{
SOAR Innovation Approach to Creating Strategies Formulation to Drive Sport Ecosystem in Thailand
}

\author{
${ }^{1}$ Penprapa Teeranuwat ${ }^{(D *}$, ${ }^{1}$ Somthop Thithathan ${ }^{(i)}$ \\ ${ }^{1}$ Faculty of Social Sciences and Humanities, Mahidol University, Salaya, Nakhonpathum, Thailand.
}

Submitted 14 May 2021; Accepted in final form 27 July 2021.

\begin{abstract}
Background. It cannot be denied that sport ecosystem consists of complex stakeholders. According to that, smart orchestration was needed to permit integration and promote active cross-sectoral. It required a suitable strategy to integrate and engage the entire system at any individual group, enterprise-level, and public sector. Therefore, the practical strategy will engage the entire system, so that key stakeholders participate, engage or commit to creating shared values that are essential to driving a strategy together. Moreover, it is imperative to engage stakeholders from the start to assigned duties and establishing a connection between departments efficiently. So, the research study focused on using the SOAR approach (strengths, opportunities, aspirations, and results) as a tool for establishing a dialogue with complex stakeholders in Thailand's sports ecosystem that consist of 3 main groups of stakeholders which were government sector, private sector, and content providers. Objectives. The research study aims to create strategies formulation to drive the sports ecosystem as a tool in integrating collaboration of sports ecosystem in Thailand. Methods. The in-depth interview with 25 key informants and confirmed strategies in a focus group with 8 expertise has been used in this research. Results. It found that 5 effective strategies exalted operation by increasing integration among complex stakeholders in Thailand's sports ecosystems. Conclusion. Thailand's sports ecosystem accurately to inquiry, strengthen, imagine opportunities, innovate aspiration and inspire results and lead them seeing the same target to integrate into the implementation level to achieve the national sport development plan altogether.
\end{abstract}

KEYWORDS: Sports Ecosystem, SOAR, Integration, Strategies.

\section{INTRODUCTION}

The National Sports Development Plan No. 6 (B.E. 2560 - 2564) gathered the participants from all sport sectors to plan and created awareness and understanding of the plan to implementation. It cannot be denied that, Thailand's sport ecosystem consists of multi-level which were organizations in government level and private agencies levels were operate in development of nation's sports together. According to the scope of responsibilities of each sector by connecting with the plan according to the strategy in their own organization which had a role related to the development of the nation's sport strategist plan.
The key departments of each strategy were coordinated with various supporting agencies at the operational level. Moreover, a local supporter is involved with both government agencies and private sectors such as ministries, educational institutions, local government organizations, sports associations, non-profit organizations and a large number of private sector and related parties. Therefore, it had problems in promoting, supporting and facilitating operations efficiently, due to the understanding of the complex strategic plan which overlap in each agencies' strategy plan, and inconsistent with the strategic plan of

*. Corresponding Author:

Penprapa Teeranuwat, M.Sc.

E-mail: p.teeranuwat@yahoo.com 
the support agencies. Moreover, there are problems of response in coordination at the operational level. It cannot be denied that, it causing problems in the process to achieve the goal target (1).

In this regard, the National Sport Development Plan No. 6 will terminate in B.E. 2564 and it will be considered the outcome results to meet the objectives. If the National Sport Development Plan No. 6 is evaluated as unsuccessful and finds the same problem as the previous National Sports Development Plan, that means, we are trapped in the National Sports Development Plan from B.E. 2531 to 2564 for a total of more than 3 decades. Furthermore, the important thing in this article is not "Quality in regional sports tourism", it is the "network approach to strategic quality management". For example, there was a research explained in the area of the RST that on quality management in regional sports tourism is deficient (2). For example, there a previous studied a multiple case study approach explores two sailing clusters in France and New Zealand which the results show that interorganisational relationships tend to be formalised, while interorganisational networks tend to be informal (3). Another research was to develop deductively a conceptual framework for the detection and analysis of sport clusters (4). Last one was the research that studied the sport value framework which the result provided a new logic for value creation in sport based on the Service-dominant logic (5).

This study tried to solve such problems by using SOAR approach to created strategies to integrate those main 3 groups - government sector, private sectors, content providers, who were stakeholders in Thailand's sport ecosystem. The study examines how SOAR integrates those complex stakeholders.

\section{MATERIALS AND METHODS}

The study was qualitative research used indepth interviews and focus groups. The purposive sampling 25 key informants who are decision making in organizations in those significant 3 groups of stakeholders by using structure interview questions. The researchers gathered data from in-depth interviews by using SOAR (strengths, opportunities, aspirations, and results) approach. The structure interview questions were used and analyzed to be a (draft) strategies. Next, the (draft) strategies were verified by 8 expertise who are expertise in sport management, strategy planning, key decision maker both in public and private sectors.

Participants. 25 key informants who are decision making in organizations in those significant 3 groups of stakeholders which are government sector, private sectors and content providers. The 25 key informants were showed in Table 1.

Instruments. Data analysis adopted the principle of SOAR to obtained the (draft) of strategies formulation to drive the sports ecosystem in Thailand.

Analysis of the Step 1: Data analysis adopted the principle of SOAR analysis by accumulate and finding consistent aspect of SOAR of stakeholders were showed in the Table 2.

Table 1. The 25 Key Informants

\begin{tabular}{|c|c|}
\hline Number & Key Informants \\
\hline 3 & $\begin{array}{l}\text { 1. Inspector-General of the Ministry of Tourism and Sports, Director-General of the Department of Physical } \\
\text { Education, Governor of the Sport Authority of Thailand }\end{array}$ \\
\hline 3 & $\begin{array}{l}\text { 2. Director of sport science office of the Department of Physical Education, Director of the Sport Science } \\
\text { Department of the Sport Authority of Thailand, Dean of the Physical Fitness and Sport Clinic of Sport Science } \\
\text { Faculty. }\end{array}$ \\
\hline 3 & $\begin{array}{l}\text { 3. Managing Director or Marketing Manager of a manufacturer of sports apparel /sports equipment /dietary } \\
\text { supplements. }\end{array}$ \\
\hline 3 & $\begin{array}{l}\text { 4. President of the sport association, Manager of the competition management department or Secretary of sport } \\
\text { association. }\end{array}$ \\
\hline 3 & $\begin{array}{l}\text { 5. Managing Director of the sport product distributors, Managing Director of the product or service provider } \\
\text { company / Services company for organizing exhibitions or events. }\end{array}$ \\
\hline 3 & $\begin{array}{l}\text { 6. Director of business and right department of the State Enterprise, Director of Youth Center or National Sport } \\
\text { Stadium. }\end{array}$ \\
\hline 1 & 7. Manager of Sport Division or Sports content copyright auction. \\
\hline 1 & 8. Manager of the sport marketing development of sport media company. \\
\hline 1 & 9. Senior manager of sport marketing development. \\
\hline 1 & 10. Senior manager of sport marketing department or Manager of the sport business consultancy company. \\
\hline 1 & 11. Professional Athletic. \\
\hline 2 & 12. Manager of a sport club and/or Head of sport trainer. \\
\hline
\end{tabular}


Table 2. SOAR of Stakeholders

\begin{tabular}{lc}
\hline SOAR & Aspects \\
\hline Strength (S) & $\begin{array}{r}\text { S1. All stakeholders have potential and play important role in national sport structure. S2. Sports as a tool } \\
\text { for development of national human resources and economic. S3. Sufficient resources S4. Efforted in } \\
\text { reduce obstacles and increase fluency in operation level in interorganizational. S5. There are strength } \\
\text { networks both in public and private sectors. }\end{array}$ \\
$\begin{array}{l}\text { Opportunities } \\
\text { (O) }\end{array}$ & $\begin{array}{r}\text { O1. Cooperation within the sports ecosystem. O2. Obtaining beneficial by involved in the sport } \\
\text { ecosystem. O3. To optimize the use of resources for the most benefit to all stakeholders. O4. Integration } \\
\text { by communicated at operation level. O5. Building relationships of network among stakeholders. }\end{array}$ \\
Aspirations (A) & $\begin{array}{r}\text { A1. Committed to cooperating and responsible for their roles with full effort. A2. Intended to achieve } \\
\text { mission and objective goals of National Sport Plan. A3. Purposed to bring potential and resources of all } \\
\text { stakeholders in operational. A4. Committed to interact by communicate in creating understanding } \\
\text { implementation process. A5. Willingness to induce network and connect to cooperation in all level. } \\
\text { R1. The government sector be leader to coordinate and integrated all stakeholder managing priority of } \\
\text { problem and allocate resources. R2. Agreement among stakeholders to cooperate in derived national sport } \\
\text { and outcome must accomplish in any objective goal of the stakeholder organization's strategies. R3. } \\
\text { Mobilize all resources and manage with most beneficial. R4. Acknowledged and communicate to solve } \\
\text { obstacle in implementation. R5. Develop an existing network and maintain good relationship in intra- } \\
\text { ecosystem and inter-ecosystem for sustainability. }\end{array}$ \\
\hline
\end{tabular}

\section{RESULTS}

The (draft) strategies were created by attaching data code on each aspect of SOAR and matching aspect of Strengths (S), Opportunities (O), Aspirations (A) and Results (R). The 5 strategies by matching each aspect are as follows:

(Draft) Strategy 1: Value co-creation created by matching aspects of $\mathrm{S} 2, \mathrm{O} 2, \mathrm{~A} 2$ and $\mathrm{R} 2$.

(Draft) Strategy 2: Collaboration elevated created by matching aspect of S1, O1, A1 and R1.

(Draft) Strategy 3: Communication enhancement created by matching aspect of S3, O3, A3 and R3.

(Draft) Strategy 4: Mobilization resources created by matching aspect of S4, O4, A4 and R4.
(Draft) Strategy 5: was strengthening and expanding the network created by matching aspect of S5, O5, A5 and R5.

Participants. (Draft) of 5 strategies from a focus group was verified with 8 expertise The criteria for selecting a group of key informants must be knowledgeable and experience in building strategies, specialist in sports management, government agencies who are the chief executive of the structure of the National Sports Development Plan, the private sector who manages the company in the sports industry and sports association president. The 8 expertise were showed in Table 3.

Table 3. The 8 Expertise

\begin{tabular}{lc}
\hline Number & Key Informants \\
\hline $\mathbf{1}$ & 1. Chief Executive of Sports Policy and Planning Department of Sport Authority Thailand. \\
$\mathbf{1}$ & 2. Senior Executive of Department of Physical Education. \\
$\mathbf{1}$ & 3. Sport Association President. \\
$\mathbf{1}$ & 4. Chairman of the Sports Industry Cluster Network Development Project. \\
$\mathbf{1}$ & 5. Executive planning specialist and development of sport professional business. \\
\hline
\end{tabular}

Instrument. The (Draft) strategies formulation to drive sport ecosystem in Thailand was presented to expertise in focusing group to verify the strategies by using questions and gathering opinion in each strategy from expertise.

Analysis of the Step 2. The 5 strategies were verified as follows: Strategy 1: Value co-creation related to the key informant $A$ who indicated that "Every stakeholder willing to be a part of the ecosystem because of value co-creation exactly and the stakeholder know that everyone got benefit from the dynamic of ecosystem". Strategy 2: Collaboration elevated related to the key informant $\mathrm{A}$ and $\mathrm{C}$ who expressed that "It can be seen the relationships of those 3 groups of stakeholders in two dimensions, which are cooperation and competitors whatever. Anyway, they are cooperated because of survival reason. They are sacrifice for long-term growing sustainable within whole ecosystem". Strategy 3: Communication enhancement related to the key informant B said that "the government should 
enhance communication potential, and we need more simply of communication tactics to solve lack of integration problem. We need to make clear and understand in implementation level and examine operation periodically". Strategy 4: Mobilization resources related to the key informant D and E revealed that "We have to share resources. Whenever, we entered resources, contribution will be dispersing to all stakeholders". Strategy 5: Strengthening and expand network related to the key informant $F, G$ and $\mathrm{H}$ who discussed that "I agree that connecting and strengthen network and then expansion. Everyone has their own network; we will bring it in connecting to each other".

Results. 5 strategies value co-creation, collaboration elevated, communication enhancement, mobilization resources, strengthening and expanding network were appropriate strategies formulation to drive Thailand's sport ecosystem.

\section{DISCUSSION}

The findings of this study are consistent with previous research which presents effectiveness strategies using in multicultural organization of ecosystem

Strategy 1: Value co-creation able to cocreation of value within the customer network actor is one of two stages of strategies in terms of marketing solution (6). Value is also co-created for the benefit of the provider, especially in a business-to-business context (7). Moreover, sets of value are creating relationships connected to a particular actor (8). In addition, co-create value might be able to commercialize customer-tocustomer-interaction (CCI) in a sports club which can be also used for the measurement of cocreated value in all forms of spectator sport as well (9). However, value co-creation is the active involvement of managers at all levels and every employee (10). Lastly, value co-creation strategy can be integrating various stakeholders in ecosystem, the result showed that the customer is explicitly at the same level of importance as the company as co-creators of value (11).

Strategy 2: Collaboration elevated establish the ecosystem organized and combined with public sector interests and private sector businessoriented actions. Moreover, collaboration interacts and collaborates toward a shared aim of the whole innovation ecosystem (12). However, a purely collaborative basis is becoming a global phenomenon, new forms could be successfully implemented into the innovation ecosystem (13). This finding is consistent with that

Of Dickson, Werner, and Milne who reported the three key features of the collaborative capacity framework are network structure, tie strength and collaborative inertia (14). Furthermore, with collaboration between different levels and a huge amount of public institutions and organizations, they share their expertise and collaborate to improve the whole administration (15). Nevertheless, the strategy was challenged in an ecosystem which consists of different kind systems to adopt a coopetitionbased growth strategy (16). According to that, these ecosystems both cooperate and also compete at the same time which is often seen in business ecosystems.

Strategy 3: Communication enhancement demand smart orchestration approach implies active cross-sectoral communication to reduce overall ambiguity, coupling the sector-specific needs and requirements for a unified ecosystem structure, leading the shared development of the pro-innovation culture and connects processes towards regional ecosystem excellence. However, effective communication is essential to the success of collaborative ecosystem management projects (17). A similar finding was reported by Werner, Dickson, and Hyde who reported the significant opportunities of a megaevent to strengthen existing relationships among organisations involved, and to build a valuable portfolio of both strong and weak ties. RWC 2011 positively impacted on intra-regional relationships as opposed to inter-regional relationships (18). Moreover, qualified communications specialists require to design and monitor the development of shared cognition among organization members in order to improve the effectiveness of communication and crossdisciplinary integration (19). Besides, communication has a role in constructing and sustaining a fertile culture for innovations (20) as well as in maintaining trust of dynamic multichannel networks of researchers, funders, entrepreneurs and experts (21) and organizational efficiencies (22). In addition, the crucial role of communication, participation and collaboration across different stakeholders, are implement and enhance the democratization. (23). Furthermore, companies in the business ecosystem that are 
aware of this tendency capable to ensuring that training, internal communication and even management structures focus on integration (24).

Strategy 4: Mobilization resources channeling ecosystem resources is a comprehensive ecosystem development approach to boost regional innovation creation capacity. Moreover, resource integration is a process that occurs when value propositions attract actors to share their resources during collaborative activities and interactions (25). As well as, a combination of the overwhelming number of resources supports learning in the ecosystem (26). However, it will be negotiated the exchange of their complementary resources and capabilities as well (27). The sharing and combining of resources from several firms creates new opportunities for sport as entertainment involves mobilizing and allocating tangible and intangible resources to meet cheerful and satisfied (28).

Strategy 5: Strengthening and expanding network strategy has implications for network management of the ecosystem (29). Another research conducted in the area of governance which reported that all three forms of governance (organizational, systemic, and political) have contributed to our understanding of sport governance (30). Moreover, an advantage in networking in the ecosystem is to facilitate joint learning across the network, and engineering effective ways to capture profit (31). Furthermore, network centrality of the mobile ecosystem is respect to technological knowledge (32). Besides, transnational co-innovation networks to achieve full synergy of the networks (33). In addition, network structures represent a broad set of collaborative approaches that are useful for bringing stakeholders together (34).

\section{CONCLUSION}

The study found 5 strategies to integrate implementation among complex stakeholders in Thailand's sport ecosystem. The strategies are 1) value co-creation 2) collaboration elevated 3 ) communication enhancement 4) mobilization resources 5) strengthening and expanding network. It can be said that, the most influential strategy is value co-creation because value cocreation will be integrated collaboration, resources and connect networks of the ecosystem through various levels such as micro, meso, and macro level. The limitation of the research ecosystem is a new concept in Thailand, so it needs more explanation to inform the interviewee to understand the concept of ecosystem.

\section{APPLICABLE REMARKS}

- Relevant agencies can apply these cognitive to be guideline for the development of the sports ecosystem in Thailand.

- Strategies are tool to strengthen the implementation and to integrated function until achieving the vision and missions of the National Sport Development Plan.

\section{REFERENCES}

1. Office of the Permanent Secretary. The National Sports Development Plan No.62017

2. Wasche H, Dickson G. Quality in regional sports tourism: A network approach to strategic quality management. J SportTourism. 2013;18(2):81-97. doi: 10.1080/14775085.2013.826593

3. Gerke A, Babiak K, Dickson G, Desbordes M. Developmental processes and motivations for linkages in cross-sectoral sport clusters. Sport Manage Rev. 2018;21(2):133-146. doi: 10.1016/j.smr.2017.05.005

4. Gerke A, Desbordes M, Dickson G. Towards a sport cluster model: The ocean racing cluster in Brittany. Europe Sport Manage Quarter. 2015;15(3):343-363. doi: 10.1080/16184742.2015.1019535

5. Gerke A, Woratschek H, Dickson G. The sport cluster concept as middle-range theory for the sport value framework. Sport Manage Rev. 2019. doi: 10.1016/j.smr.2018.12.004

6. Cova B, Salle R. Marketing Solutions in Accordance with the S-D Logic:Co creating Value with Customer Network Actors. Indust Market Manage [Internet]. 2008;37(3):270-277. doi: 10.1016/j.indmarman.2007.07.005

7. Gerke A, Woratschek H, Dickson G. How is value co-created in a sport business-to-business context? Sport Business Manage Int J. 2020;10(4):403-430. doi: 10.1108/SBM-04-2019-0032

8. Akaka MA, Vargo SL, Lusch RF. The Complexity of Context: A Service Ecosystems Approach for International Marketing. J Int Market. 2013;21(4):1-29. doi: 10.1509/jim.13.0032

9. Chatrath S. Customer-to-customer interaction in service eco-systems - measuring its contribution to customer value and the customers' willingness-to-pay for in case of a sport event provision. [Internet]. 
ESMQ 2013 Special Issue: Value co-creation in sport management. 2013 [Cited 2020 December 22]. Available from:

https://www.dlm.uni-

bayreuth.de/pool/dokumente/Chatrath_2012_Customer_to_customer_interaction.pdf.

10.Ramaswamy V. Leading the transformation to co-creation of value. Strategy Leadership [Internet]. 2009;37(2):32-37. doi: 10.1108/10878570910941208

11.Payne AF, Storbacka K, Frow P. Managing the co-creation of value. J Academ Market Sci [Internet]. 2008;36:83-96. doi: 10.1007/s11747-007-0070-0

12.Su Y, Zheng Z, Chen J. A multi-platform collaboration innovation ecosystem: the case of China. Manage Decision [Internet]. 2018;56(1):125-142. doi: 10.1108/MD-04-2017-0386

13. Gamidullaeva L. Towards combining the innovation ecosystem concept with intermediary approach to regional innovation development. MATEC Web of Conferences. 2018;212(1):1-12. doi: 10.1051/matecconf/201821209017

14.Dickson G, Werner K, Milne S. Collaborative capacity to develop an events portfolio within a small island development state: The Cook Islands. J Polic Res Tourism Leisure Event. 2017;10(1):69-89. doi: 10.1080/19407963.2017.1409751

15.García-Holgado A, García-Peñalvo FJ. Knowledge management ecosystem based on Drupal platform for promoting the collaboration between public administrations. TEEM '14: Proceedings of the Second International Conference on Technological Ecosystems for Enhancing Multiculturality [Internet].2014.

16. Aalderinga LJ, Lekerab J, HoonSongb C. Competition or collaboration? - Analysis of technological knowledge ecosystem within the field of alternative powertrain systems: A patent-based approach. $J$ Clean Product. 2019;212:362-371. doi: 10.1016/j.jclepro.2018.12.047

17.Jakobsen $\mathrm{CH}$, McLaughlin WJ. Communication in ecosystem management: a case study of crossdisciplinary integration in the assessment phase of the interior Columbia Basin Ecosystem Management Project. Environ Manage. 2004;33(5):591-605. doi: 10.1007/s00267-003-2900-2 http://ncbi.nlm.nih.gov/pubmed/15129362

18. Werner K, Dickson G, Hyde K. The impact of a mega-event on inter-organisational relationships and tie strength: Perceptions from the 2011 Rugby World Cup. Sport Manage Rev. 2015;18(3):421-435. doi: 10.1016/j.smr.2014.11.005

19.Luoma-aho V, Halonen S. Intangibles and Innovation: The Role of Communication in the Innovation Ecosystem. Innovat J [Internet]. 2010;7(2):1-20.

20.Ahmed PK. Culture and climate for innovation. Europe J Innovat Manage [Internet] 1998;1(1):30-43. doi: 10.1108/14601069810199131

21.Ellonen R, Blomqvist K, Puumalainen K. The role of trust in organizational innovativeness. Europe $J$ Innovat Manage [Internet]'. 2008;11(2):160-181. doi: 10.1108/14601060810869848

22. Moenaert RK, Caeldries F, Lievens A, Wauters E. Communication Flows in International Product Innovation Teams. J Prod Innovat [Internet]. 2000;17(5):360-377. doi: 10.1111/1540-5885.1750360

23.Dicka J, Turkelboomb F, Woodsa H, Iniesta-Arandiac I, Primmerd E, Saarelad S. Stakeholders' perspectives on the operationalization of the ecosystem service concept: Results from 27 case studies. Ecosystem Service [Internet]. 2018:552-562. doi: 10.1016/j.ecoser.2017.09.015

24. Stone M. The new (and ever-evolving) direct and digital marketing ecosystem. $J$ Direct Data Digital Market Practice [Internet]. 2014;16(2):71-72. doi: 10.1057/dddmp.2014.58

25.Frowa P, McColl-Kennedy JR, Payne A. Co-creation practices: Their role in shaping a health care ecosystem. Indust Market Manage [Internet]. 2016;56(23-4). doi: 10.1016/j.indmarman.2016.03.007

26. Majd S, Marie-Hélène A. System of Information Systems as Support for Learning Ecosystem. Emerging Technol Educat [Internet]. 2017:29-37. doi: 10.1007/978-3-319-71084-6_4

27. Gaur A, Ondrus J. The role of banks in the mobile payment ecosystem: a strategic asset perspective. Proceedings of the 14th Annual International Conference on Electronic Commerce.2012.

28.Da-Silva EC. Sports ecosystems: Assumptions for incorporating marketing strategies in sports clubs. Market Rev [Internet]. 2017;17(4):409-426. doi: 10.1362/146934717X14909733966281

29. Aarikka-Stenroos L, Ritala P. Network management in the era of ecosystems: Systematic review and management. Indust Market Manage [Internet]. 2017;67:23-36. doi: 10.1016/j.indmarman.2017.08.010

30.Dowling M, Leopkey B, Smith L. Governance in sport: A scoping review. J Sport Manage. 2018;32(5):438-451. doi: 10.1123/jsm.2018-0032 
31.Williamson PJ, De-Meyer A. Ecosystem Advantage: How to Successfully Harness the Power of Partners. California Manage Rev [Internet]. 2012;55(1):24-46. doi: 10.1525/cmr.2012.55.1.24

32.Lee S, Kim W, Lee H, Jeon J. Identifying the structure of knowledge networks in the US mobile ecosystems: patent citation analysis. Technol Anal Strategic Manage [Internet]. 2015;28(4):1-24. doi: 10.1080/09537325.2015.1096336

33.Cai Y, Ferrer BR, Lastra JM. Building University-Industry Co-Innovation Networks in Transnational Innovation Ecosystems: Towards a Transdisciplinary Approach of Integrating Social Sciences and Artificial Intelligence. Sustainabil [Internet]. 2019;11:2-23. doi: 10.3390/su11174633

34. Willis CD, Riley BL, Best A, Ongolo-Zogo P. Strengthening health systems through networks: the need for measurement and feedback. Health Policy Plan. 2012;27 Suppl 4:iv62-66. doi: 10.1093/heapol/czs089 http://ncbi.nlm.nih.gov/pubmed/23014155 